\title{
A study on effect of dietary counselling on COPD patients
}

\author{
NEHA SHARMA, ANKITA TYAGI AND RITA BAKSHI
}

Received: 05.07.2016; Revised: 03.10.2016; Accepted: 18.10 .2016

See end of the paper for authors' affiliations

\section{ANKITA TYAGI}

Department of Home Science, S.V.

Subharti University, MEERUT (U.P.) INDIA

Email : tyagiankita20@gmail.com
-ABSTRACT : The prevalence of chronic obstructive pulmonary disease (COPD) have gone through significant changes over the past decade. This article examines how the treatment and management of COPD has become more individualized. In addition, complications and medication are evaluated and the importance of diet including the patient perspective when designing a treatment plan is discussed. Finally, new advances in technology and research, clinical communication, exercise and disease education is introduced which helps in the efforts on COPD management.

KEY WORDS: Prevalence, Significant, Complication, Medication, Technology

- HOW TO CITE THIS PAPER : Sharma, Neha, Tyagi, Ankita and Bakshi, Rita (2016). A study on effect of dietary counselling on COPD patients. Asian J. Home Sci., 11 (2) : 341-345, DOI: 10.15740/ HAS/AJHS/11.2/341-345. 